Published on Reviews in History (https://reviews.history.ac.uk)

\title{
Cultural Left and the Reagan Era: US Protest and Central American Revolution
}

Review Number: 1948

Publish date: Thursday, 16 June, 2016

Author: Nick Witham

ISBN: 978-1784531966

Date of Publication: 2015

Price: $£ 62.00$

Pages: 320pp.

Publisher: I. B.Tauris

Publisher url: http://www.ibtauris.com/Books/Humanities/History/History\%20earliest\%20times\%20to\%20present C0BA-4928-ACC4-415188DCDEE8\%7D

Place of Publication: London

Reviewer: Evan McCormick

Early in 2015, journalists reporting on US Democratic presidential candidate Bernie Sanders produced a potentially valuable nugget of opposition research: in 1985, Sanders visited Nicaragua as part of a delegation of US solidarity groups that was given a personal audience with Sandinista president Daniel Ortega.(1) In his first political memoir, published with Verso Books - an acknowledged Left-wing press - Sanders called the trip 'profoundly emotional'. 30 years later, the most shocking aspect of the story was not the trip itself, but that it raised few eyebrows in the US political establishment. The report seemed to confirm the enduring importance of US interventions in Central America during the 1980s, along with their conflicted place in American cultural memory.

The historical reasons for this state of affairs can be found in Nick Witham's deftly written and refreshingly concise The Cultural Left and the Reagan Era: US Protest and Central American Revolution. The book seeks to illuminate the cultural modes of resistance that sprung up in opposition to the Reagan administration's interventions in Central America, and to evaluate their importance - not just to an understanding of the age of Reagan, but the longer frame of American liberalism. Drawing on the examples of Michael Denning and Jürgen Habermas, Witham uses a social-intellectual methodology to highlight how 'cultural production' helped forge connections on the US Left between core ideas of solidarity, antiimperialism, and anti-interventionism. This focus, he argues, demonstrates not only that the radical Left withstood the rise of Reagan Republicanism; it adapted the organizational repertoires of the 1960s New Left to fashion a broad-based opposition to Reagan's anti-communist militarism in Latin America. While Witham's book illuminates the dynamics of a key period in the development of the US Left, its most powerful contributions are limited by the author's handling of the interplay between cultural factors and politics, the latter of which is too often excised from otherwise astute analysis.

The book is structured as a collection of micro histories of prominent Anglo-US leftist individuals and outlets in the areas of scholarship, journalism, and filmmaking. The basic unifying element among these voices, Witham contends, was a determination to engage with political topics central to leftist organizing while still reaching 'a broader public' (p. 14) - a fluid term that applies at times to movement activists and, 
at others, to popular audiences. Although Witham overstates the case that this diverse cast of figures represented a 'coherent bloc of cultural radicals' (p. 182) - his portrayal of historians Walter Lefeber and Gabriel Kolko, intellectuals Christopher Hitchens and Alexander Cockburn writing in The Nation, and Oliver Stone, to name but a few, belies such coherence - he does demonstrate the existence of a discernible cultural front on the Left. The author's prose is lively and economical, skillfully narrating debates over major ideas that animated the Left as well as the professional connections that empowered key cultural figures and institutions.

If there's a shortcoming in the case study format, it is that it invites Witham to employ fluctuating standards for evaluating the importance of cultural work. In the introduction, Witham writes that it was the efforts of 'cultural radicals' to reach broader audiences which 'mobilised' the core ideas of solidarity, antiinterventionism, and anti-imperialism (p. 14). In the final line of the book, Witham says his actors 'aligned themselves' with the solidarity movement and were responsible for 'representing and stimulating' opposition to US intervention in Central America (p. 189). In the intervening pages, the reader will find a range of characterizations of what cultural work was doing, from 'engaging with' activist discourse (p. 154) to 'nurturing links' between solidarity groups (p. 123), or simply 'overlap[ping]' (p. 180) with activism. Witham's determination to carve a discrete sphere for a cultural analysis of the Left ultimately blurs the focus on what he compellingly describes in the introduction as the 'relationship between cultural production and radical politics' (p. 13).

This nexus between the cultural and the political is essential for evaluating Witham's argument, for it reflects the stakes that each of his subjects perceived in their work in 1980s, even if they were not 'full-time activists' (p. 3). There is little to suggest that the editorial collective of The Guardian, for example, perceived its debate over party-building vs. movement-building (pp. 101-5) as one playing out in a cultural sphere independent of the political goal of opposing Reagan's policies. Indeed, as Witham himself shows, solidarity groups like the Committee in Solidarity with the People of El Salvador (CISPES), Nicaragua Network (NicaNet), and Witness for Peace actively drew on material produced in The Guardian and documentary films to oppose the Reagan Right and achieve solidarity with the Central American Left. At the same time, these writers, journalists, and filmmakers were anything but aloof from the solidarity movement - not simply trying to reach movement audiences but fully integrated in the debates shaping movement activism. Witham's method of isolating culture does more to obscure these important connections than to emphasize them.

This is particularly evident in the first chapter of the book, which examines the historical scholarship of Walter Lefeber and Gabriel Kolko through a cultural lens. Witham concludes that the two authors achieved 'engagement with the 1980s public sphere' (p. 41) by drawing on revisionist historical methodology to highlight the problematic roots of US intervention in Central America. This is an unsurprising conclusion, and one that downplays the divergences between the two authors: LaFeber's agency-driven approach to dependency theory which favored a 'liberal, democratic opposition' (p. 33) to Reagan's policies and Kolko's economic focus which supported 'more radical' (p. 33) support for revolutionary, anti-imperialist movements (p. 41). Given that Witham seeks to synthesize the two approaches as part of the same 'activist history of American empire,' his attention to the authors' personal experiences with radicalism is interesting but beside the point. Far more useful would be an analysis of how solidarity groups and activists - especially given LaFeber's attention to the political route - received and made use of revisionist narratives in fashioning their opposition to Reagan. The chapter's concluding note - that revisionism survived the 1980s through heterogeneous applications to the crisis of Reagan's interventions in Central America - reinforces the already-standard analysis of the academic response to Reagan's interventions, but does not deliver the 'activist history' that Witham promises.

The absence of a more sophisticated engagement with Reagan's leftist opposition represents another problem with the book. Activists and the 'movement' hover in the background as an audience for cultural producers, but rarely take shape. Whereas Witham is smart about drawing distinctions between the antiintervention and anti-imperialist modes of his cultural figures, he is less inclined to sketch the distinctions 
between the diverse groups that gave life to the cultural critiques through activism that extended beyond the solidarity that Witham is focused on. To be fair, this focus is driven by his research agenda, which explicitly highlights the work of CISPES, NicaNet and a handful of other groups to join in the struggles and travails of the Central American Left. But even a brief discussion of the wider range of movement groups would allow readers to locate this solidarity in relation to the more political means of activism employed by groups like the Washington Office on Latin American Affairs, the Council on Hemispheric Affairs, and Americas Watch.

The lack of any systematic engagement with human rights is a particularly unfortunate symptom of this scope. The language of human rights was the register in which many solidarity groups and antiinterventionist NGOs voiced their opposition to Reagan's policies. Given the outpouring of histories of human rights in recent years and, in particular, the attention to how transnational networks responded to widespread repression in Latin America, the lack of nexus between human rights and the cultural Left in Witham's analysis is glaring.(3) A discussion of human rights would also have allowed Witham to broaden the geographic scope of his study beyond the narrow focus on El Salvador and Nicaragua, given that solidarity activists in the 1980s were captivated by human rights abuses in countries like Guatemala and Honduras as well.

It is in the chapters where Witham does engage directly with the possibility of politics that his cultural approach bears the most fruit. The chapter on Verso Books, for example, shows how the British publishing imprint envisioned its efforts in political terms, producing two US series that sought to set the agenda for the 'more constructive engagement with political struggle in Central America' (p. 53). In Verso's yearbook of Leftist thought, The Year Left, Witham shows convincingly how anthropologists, economists, and other academics sought to influence directly how the solidarity community defined the political stakes of US intervention in the region. The debate that took place in those pages - 'whether or not the left should retain any faith in the ability of America's existing democratic institutions to usher in new, emancipatory forms' (p. 58) - had huge implications for the Left's preferred means of activism. In particular, as Witham points out, Verso Books became an outlet among groups on the Left for voicing a distrust of dogmatic support for revolutionary movements, a tack that helped broaden the reach of solidarity groups (p. 62). Though Witham could have done more to show whether and how publications of solidarity organizations - which were prolific producers of written material in their own right - drew on cultural material, he nonetheless shows that this was not intellectual arcana, but rather significant soul-searching among activists committed to adapting their repertoire to the challenges of Reagan's aggressive policies. 
The best chapter in the book is a case study of documentary filmmaking which shows how the works of Pamela Yates and Pamela Cohen animated a feminist critique of US intervention in Central American politics. Witham is at his most skillful when writing about film, and his history of When the Mountains Tremble and Maria's Story artfully shows how two filmmakers used documentary filmmaking to simultaneously galvanize an activist audience around the issue of gender, while also challenging broader media narratives about Central American revolutionary movements. Witham is masterful in weaving together cultural analysis with concerns of politics - both in the sense of the broader US political landscape that the films sought to influence, and the internal movement politics that conditioned the production and reception of the film. In addition to close collaboration with solidarity groups - CISPES helped Pamela Cohen 'gain access to the FMLN' while filming Maria's Story - Witham argues that choices of form and style are ones that entailed 'consciously taking sides' over a political debate (p. 159). The films were produced in ways that 'could be used as educational and propaganda tools at the same time as they gained accolades as politicised cultural work' (pp. 173 and 179). Witham could have gone even further on this point by showing how these films responded to specific policy debates underway during the Reagan administration. When the Mountains Tremble, for example, aimed to achieve a very tangible goal on the Left of resisting Reagan's efforts to overturn legislation restricting military aid to Guatemala's repressive military government. Nonetheless, Witham succeeds in showing how the funding, distribution networks, and audiences of these films helped forge a 'mutually reinforcing' relationship between anti-interventionism and feminism (p. 166).

Given that each of Witham's sections - pairs of chapters - highlight divergences within the broader Left over the specific issue of the promise of politics as a means of opposition, it is curious that the author did not undertake a more explicitly comparative methodology from the outset. Witham seems at pains to synthesize the efforts of moderate anti-interventionists and the more radical anti-imperialists into a coherent cultural 'bloc'. But a critical comparative dimension would have illuminated the most interesting question in the book: did the radical Left lose out to mainstream moderate activism in the age of Reagan, given that many in the movement grew disillusioned with revolutionary movements in Central America, or abandoned antiinterventionism entirely in the post-Cold War?

When he frontally addresses this question in the conclusion, Witham is admirably nuanced. Some of the Left's most prominent cultural voices - specifically those who were hewing away from orthodoxy in the mid-1980s - went on to become prominent supporters of liberal intervention in the Middle East. Christopher Hitchens and Paul Berman, for example, emerge in Witham's conclusion as disillusioned expatriates of the anti-interventionist struggles of the 1980s. But, as Witham shows, neither did the more radical voices Oliver Stone, for example - simply fade away. Explaining the dynamics of intellectual divergences that occurred between radicals and moderates would have allowed Witham to show not simply that these debates were happening in the 1980s, but that their outcomes determined the causes - and the regions of the world over which Leftist public intellectuals and cultural producers would be willing to take up arms after the Cold War. The anti-interventionist criticism of US foreign policy lost some its salience among cultural producers after the 1980s, Witham seems to hint, but the anti-imperialist critique of US foreign policy remained a sturdy pillar of the Left's repertoire well beyond the end of Reagan's tenure and the end of the Central American conflicts.

The reality is that, in cultural terms, the radicals' critique of US foreign policy in the Western Hemisphere of the 1980s retains powerful currency. Even as Reagan's image has undergone something of a remaking in recent years, the memory of Reagan's interventions in Central America remains overwhelmingly negative. And today, in the spheres that Witham highlights - the academy, journalism, and film - disapproval of US intervention abroad remains widespread. Bernie Sanders' Nicaragua trip is unlikely to derail his bid for the presidency, if it generates any attention at all. The riddle remains, however, as to why such resilient cultural attitudes emanating from the Left have done so little to change the basic orientation of US foreign policy and the propensity of decision-makers to wield US power in the 30 years since those regional interventions. Witham's book will provide readers with insight into the origins of that riddle, but answering it will require 
a more explicit interrogation of the relationship between culture and politics.

\section{Notes}

1. See Alex Seitz-Wald, 'The 25 Best Things we Learned from Bernie Sanders' Book', MSNBC.com, 28 May 2015 <http://www.msnbc.com/msnbc/the-25-best-things-we-learned-bernie-sanders-... [2] [accessed 3 February 2016]; Hunter Walker, 'Bernie Sanders' Radical Past: How the Vermont Firebrand Started Wearing a Suit and Gave Up on Taking Over Big Companies', Yahoo! Politics, 17 January $2016<$ https://www.yahoo.com/politics/bernie-sanders-radical-past-how-the-vermo... [3] [accessed 3 February 2016].Back to (1)

2. See Mark Berger, Under Northern Eyes: Latin American Studies and US Hegemony in the Americas (Bloomington, IN, 1995), ch. 4, 'The new Cold War', and pp. 176-83 on critical academic responses to Reagan's policies.Back to (2)

3. Although Witham does not discuss human rights, two books that he cites discuss the role of human rights activism in the fashioning of a broad leftist opposition to Reagan's Central America policy. See Roger Peace, A Call to Conscience: The Anti-Contra War Campaign (Amherst, MA, 2012) and Christian Smith, Resisting Reagan: The US Central American Peace Movement (Chicago, IL, 1996). $\underline{\text { Back to (3) }}$

The author is happy to accept this review and does not wish to comment further.

\section{Other reviews:}

$\mathrm{H}-\mathrm{Net}$

https://networks.h-net.org/node/28443/reviews/103731/iber-witham-cultural-left-and-reagan-era-us-protestand-central [4]

Source URL:https://reviews.history.ac.uk/review/1948

\section{Links}

[1] https://reviews.history.ac.uk/item/148984 [2] http://www.msnbc.com/msnbc/the-25-best-things-welearned-bernie-sanders-book\&gt; [3] https://www.yahoo.com/politics/bernie-sanders-radical-past-how-thevermont-230255076.html\&gt; [4] https://networks.h-net.org/node/28443/reviews/103731/iber-withamcultural-left-and-reagan-era-us-protest-and-central 